\title{
Analysis of Corrosion Products Transported through Secondary Side of Candu Steam Generator Using GIXRD
}

\author{
ALICE DINU ${ }^{1}$, MARIANA TUNARU ${ }^{2 *}$ \\ ${ }^{1}$ Technologies for Nuclear Energy State Owned Company (RATEN), 1 Campului Str., 115400, Mioveni, \\ Romania \\ ${ }^{2}$ Institute for Nuclear Research, 1 Campului Str., 115400, Mioveni, Romania \\ To verify the chemistry of secondary side of CANDU steam generators, Millipore filters are used to \\ sampling from condensing extraction pump, feed water header and blow down of steam generator. These \\ filters retain the corrosion products as very fine particles and are used as samples in chemistry water \\ control. X-Ray diffraction (XRD) is the most used technique that can provide information about the phase \\ composition of analyzed samples. Because the crud layers on the Millipore filters are very thin, to identify \\ the corrosion products Grazing Incidence X-Ray diffraction (GIXRD) technique was used. The following \\ compounds have identified: magnetite $\left(\mathrm{Fe}_{3} \mathrm{O}_{4}\right)$, hematite $\left(\mathrm{Fe}_{2} \mathrm{O}_{3}\right)$, and iron oxide hydroxide ( $\left.\mathrm{FeOOH}\right)$. It was \\ observed a brown-reddish background specific to hematite and iron oxide hydroxide, especially for filters \\ extracted from condensing extraction pump. The black colour of crud present on filters extracted from feed \\ water header and blow down of steam generator shows the presence of magnetite.
}

Keywords: Millipore filters, GIXRD, iron oxides

The corrosion of the materials used to manufacture the components of nuclear power plants represents the main cause for diminution of thermal transfer and for the appearance of some dysfunctions. It is possible to minimize this corrosion using the following methods:

- a judicious selection of the materials used in the construction of primary and secondary side of Nuclear Power Plants (NPP);

- A strict control of the chemistry of cooling agent.

Despite of these cautions, the corrosion products are released from the surface of structural materials and transported by cooling agent through the secondary side. A part of these corrosion products are deposed on the surface of secondary side components and formed adherent crusts or sludge deposits, in special in the restrictive flow areas [1]. These deposits of corrosion products lead to appearance of some major problems during the operation of nuclear power plant.

The current materials used to manufacture different components of secondary side of CANDU NPP are: SA 106, SA 516, SA 508, stainless steel 304 and 410, Incoloy 800 and Inconel 600 [1]. The experiments effectuated on the several type of carbon steel (SA-106, SA-508 and SA-516) in the specific environment of normal operation of secondary side have demonstrated that the magnetite is the main compound formed on the sample surface, but $\alpha$ $\mathrm{Fe}_{2} \mathrm{O}_{3}$ and $\alpha-\mathrm{Fe}_{2} \mathrm{O}_{3} \cdot \mathrm{H}_{2} \mathrm{O}$ can be present in a very small quantities [2,3]. In the same operating conditions, on the surface of stainless steel 304 and 316 spinel compounds with magnetite structure $\left(\mathrm{NiFe}_{2} \mathrm{O}_{4}, \mathrm{FeCr}_{2} \mathrm{O}_{4}\right.$ and $\left.\mathrm{Fe}_{3} \mathrm{O}_{4}\right)$, hematite $\left(\alpha-\mathrm{Fe}_{2} \mathrm{O}_{3}\right)$ or maghemite $\left(\gamma-\mathrm{Fe}_{2} \mathrm{O}_{3}\right)$ can be present [4,5]. On the surface of component manufactured from Incoloy 800 the same spinel compounds can be growing up [6]. By the Mösbauer analyses, in the crud samples taken over from different points of the secondary circuit of a CANDU NPP the following compounds were identified: magnetite $\left(\mathrm{Fe}_{3} \mathrm{O}_{4}\right)$, hematite $\left(\alpha-\mathrm{Fe}_{2} \mathrm{O}_{3}\right)$, maghemite $\left(\gamma-\mathrm{Fe}_{2} \mathrm{O}_{3}\right)$ and goethite $(\alpha-\mathrm{FeOOH})$ [7].

Even if the corrosion of the structural materials used in secondary side cannot be eliminated, it is possible to maintain the corrosion process in desirable ppb limits. To control the corrosion products transported by the cooling agent into a CANDU NPP secondary side Millipore filters are used. The Millipore filter is a uniform, continuous mesh of polymeric material with precisely defined pore size, $45 \mu \mathrm{m}$ in the case of CANDU NPP. The identification and characterization of corrosion products, retained on the Millipore filters from different parts of secondary side, give information that can be used to control and mitigate the corrosion process in the secondary side of a CANDU NPP.

$\mathrm{X}$-Ray diffraction (XRD) technique is a very useful method to identify and quantify different corrosion products. Furthermore, XRD can distinguish between different modifications of phases that have the same chemical formula. For example, goethite, lepidocrocite, feroxyhydrite and akaganeite can be differentiating, even though they all have the same chemical formula. The identification of phase compositions is crucial to understand the corrosion processes and establish specific solutions to mitigate corrosion.

In this paper, we used Grazing Incidence X-ray Diffraction (GIXRD) to characterize the nature of corrosion products transported through the secondary side of a CANDU NPP and their evolution in time.

*email: alice.dinu@nuclear.ro 


\section{Experimental part}

Millipore filters from condensing extraction pump (CEP), from feed water header (FW) and blow down of steam generator (BLD) (Figure1), extracted at every 7 days, for a period of 2 month, were investigated by X-ray diffraction and optical microscopy. Because the crud layer retained on the Millipore filters were very thin, the Grazing Incidence X-ray Diffraction method was used.

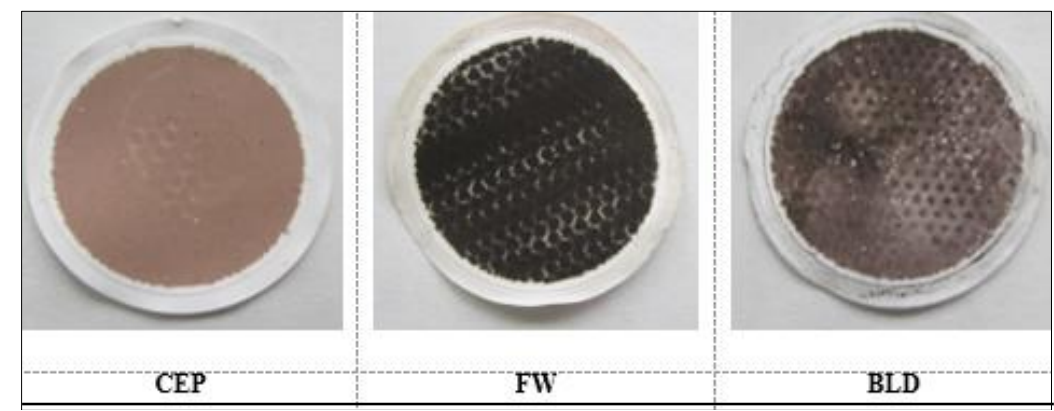

Fig. 1. Examples of Millipore filters exposed in different points of secondary side of a CANDU NPP

The common technique used in the X-ray diffraction analysis does not allow thin film analysis due to the fact that the intensity of the reflected beam from the analysed layer is very small (the analysed volume is very small) compared with the intensity of the background or of the diffraction peaks corresponding to the substrate. The most common used focusing configuration is the Bragg-Brentano geometry (or $\theta-2 \theta$ geometry), presented in Figure 2a [8]. In this geometry, the receiving slit and the X-Ray source must be placed on the diffractometer circle, having the centre exactly on the sample. The modern diffractometers allow the use the $\theta-\theta$ geometry, when the X-ray source and the detector move simultaneously over the angular range $\theta$. In the case of common XRD techniques a monochromatic divergent beam is used.

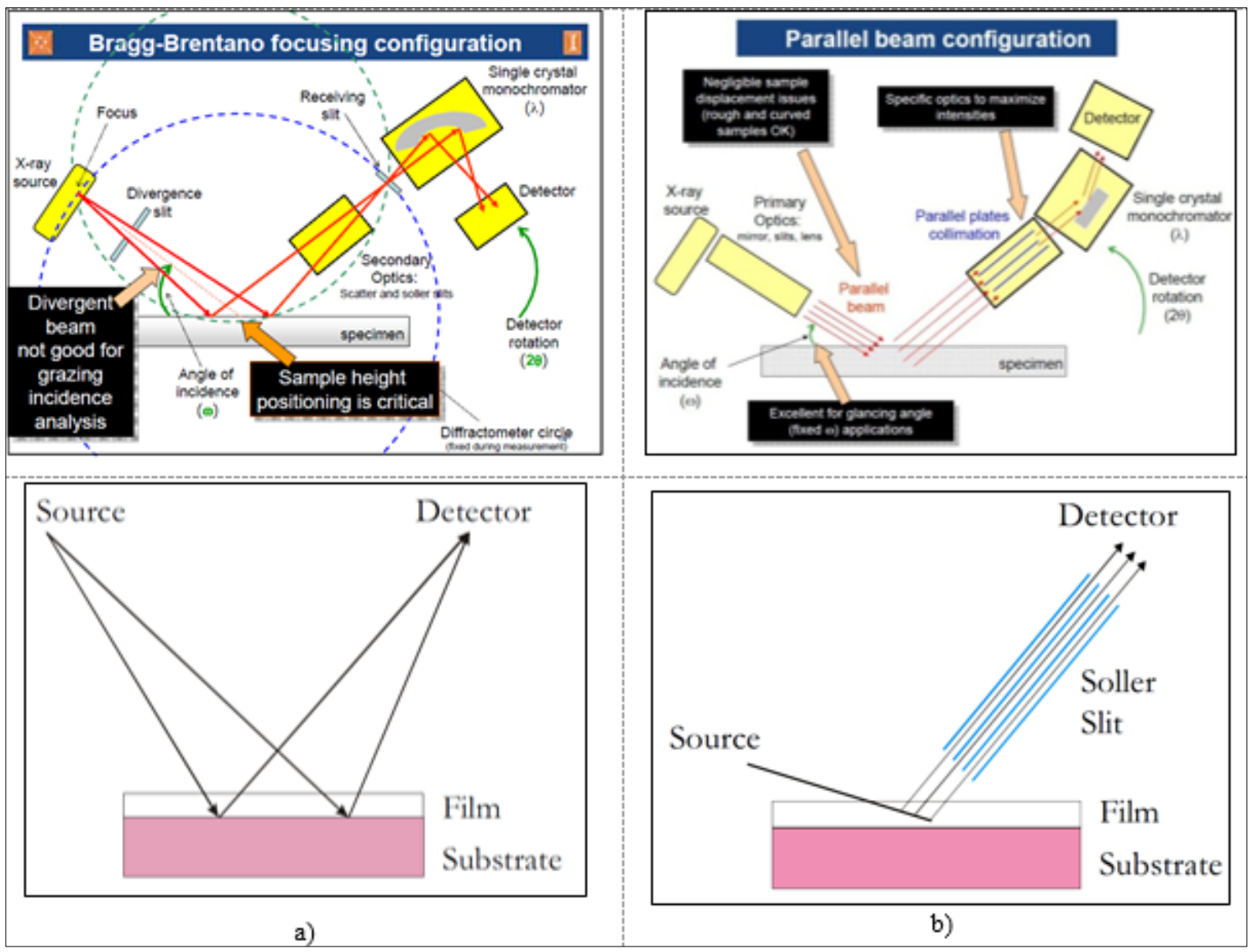

Fig. 2 The difference between Bragg-Brentano focusing configuration (a) and parallel beam configuration used in the GIXRD geometry (b) [8] 
Diffraction at small angles (Grazing Incidence X-Ray Diffraction-GIXRD) was developed by Marr, Eisenberger and Cho in 1979 to analyse thin films deposited on a substrate [9]. In this case, the incident angle is fixed at a very small value (typically between $\omega=0.3^{\circ}$ and $3^{\circ}$ ) and does not changes during the analysis. Therefore, the X-ray tube remains fixed and only the detector is rotated with a $2 \theta$ angle (Figure $2 b$ ). In this way, we obtain the increase of the Xray beam path in the thin film and, hence an increased intensity of the diffracted beam by the thin layer. The penetration depth normal to the surface is proportional to the sinus of the angle of incidence [10], as long as the angle of incidence is larger than the critical angle (the angle of total external reflection). To be able to use the GIXRD, both the incident beam and the diffracted beam must be plane parallel (not divergent). This is possible using either narrow slits or Göbel mirrors in the incident beam path, in combination with a plane parallel collimator in the diffracted beam path. The collimator allows only quasi-parallel beam to reach the detector.

In this work, GIXRD analyses were performed using a PanAlytical X'Pert Pro MPD diffractometer. It was used a $\mathrm{Cu}_{\mathrm{K} \alpha}$ radiation $\left(\lambda_{\mathrm{K} \alpha 1}=1.5418 \AA \AA\right.$ ), a divergence slit of $1 / 8^{\circ}$ and a $10 \mathrm{~mm}$ mask for the incident beam, respectively a plan parallel collimator of $0.27^{\circ}$ and a Ni large filter (to minimise the $\beta$ radiation) for the diffracted beam. The angle of incidence was choose for each sample, function of oxide layer, and varied between $2^{0}$ and $5^{0}$. To identify the iron oxides presents on the Millipore filters and to estimate the amount of each compound in the crud the High Score Plus software was used.

\section{Results and discussions}

By X-Ray diffraction, on the surface of Millipore filters extracted from condensing extraction pump (CEP) was put in evidence the presence of the following compounds: magnetite $\mathrm{Fe}_{3} \mathrm{O}_{4}$, with cubic or orthorhombic crystallographic system; hematite $\mathrm{Fe}_{2} \mathrm{O}_{3}$ with rhombohedra or tetragonal crystallographic system; iron oxide hydroxide $\mathrm{FeOOH}$ (cubic or orthorhombic crystallographic system); and $\mathrm{Fe}_{1.67} \mathrm{H}_{0.99} \mathrm{O}_{3}$, with rhombohedra crystallographic system, that is a form of hematite (Figure 3).

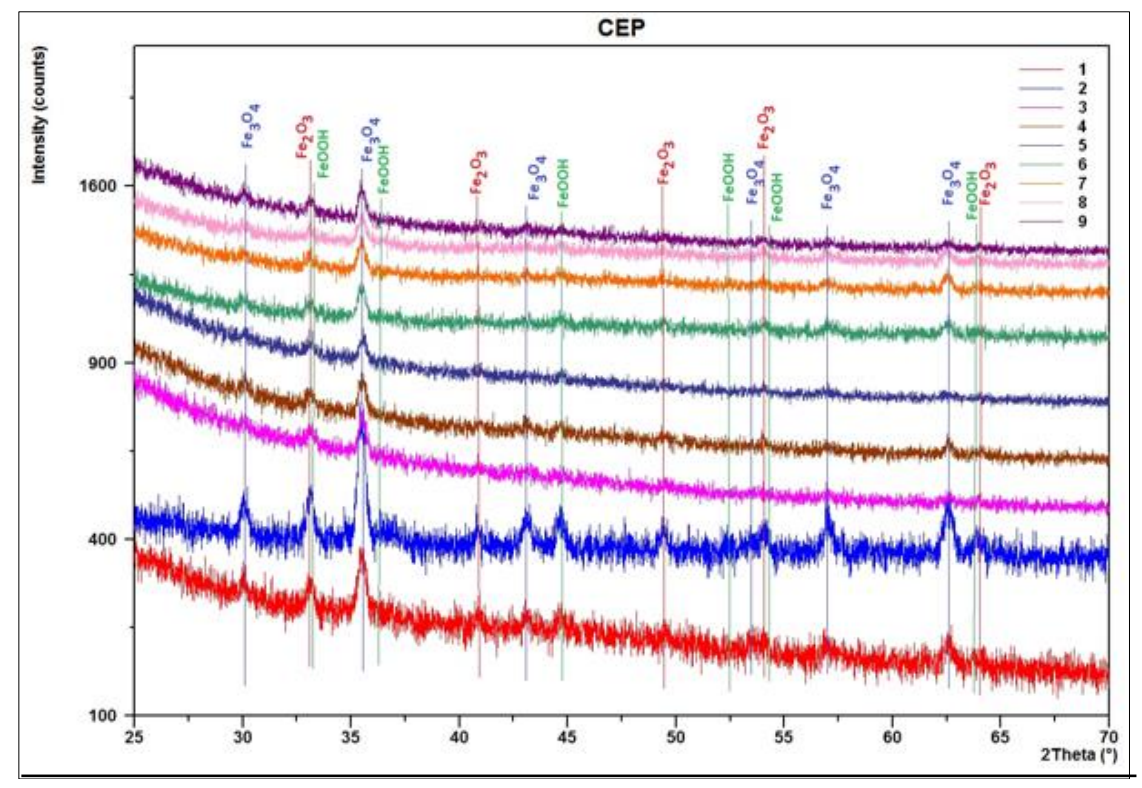

Fig. 3 Superposing of X-Rays spectra corresponding to the all Millipore filters extracted from condensing extraction pump (CEP)

Starting with the third sampling, it was found that the percentage of magnetite remained almost constant, in the range of $41-46 \%$ (Figure 4). It has also been noted, that the percentage of lepidocrocite is reduced (from 26\% to 11\%), probably due to the transformation of lepidocrocite into hematite by thermal dehydration, as a result of the increasing of the temperature along the cooling water line. Thus, the percentage of hematite increases from $23 \%$ to $46 \%$.

The crud retained at the surface of filters extracted from feed water header $(\mathrm{FW})$ contains the following oxides: magnetite (cubic system) and, also a sub stoichiometric form of magnetite $\mathrm{Fe}_{2.964} \mathrm{O}_{4}$ with cubic crystallographic system; rhombohedra hematite; maghemite $\mathrm{Fe}_{2.67} \mathrm{O}_{4}$ crystallized in cubic system; and iron oxide hydroxide $\mathrm{FeOOH}$, crystallized in cubic crystallographic system. The superposition of X-Rays spectra from filters extracted periodically is presented in Figure 5. Although the presence of lepidocrocite was initially emphasized, the conditions for the transformation of $\mathrm{FeOOH}$ in $\mathrm{Fe}_{3} \mathrm{O}_{4}$ were created, the magnetite concentration keeping almost constant, around 69\% (Figure 6). There were no significant variations in the percentage of hematite, which remained around 28\% (Figure 6). 


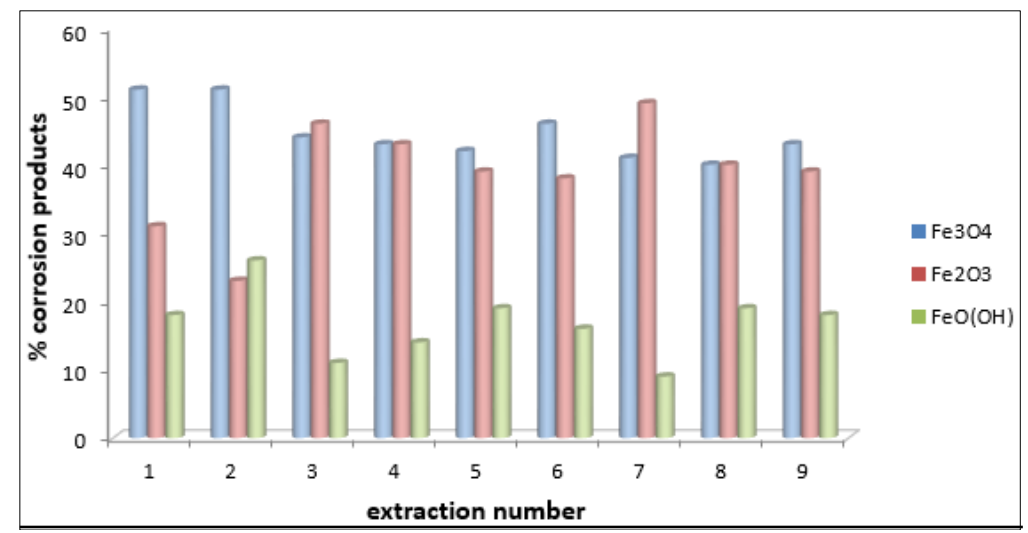

Fig. 4 The crud composition on the Millipore filters extracted from condensing extraction pump (CEP)

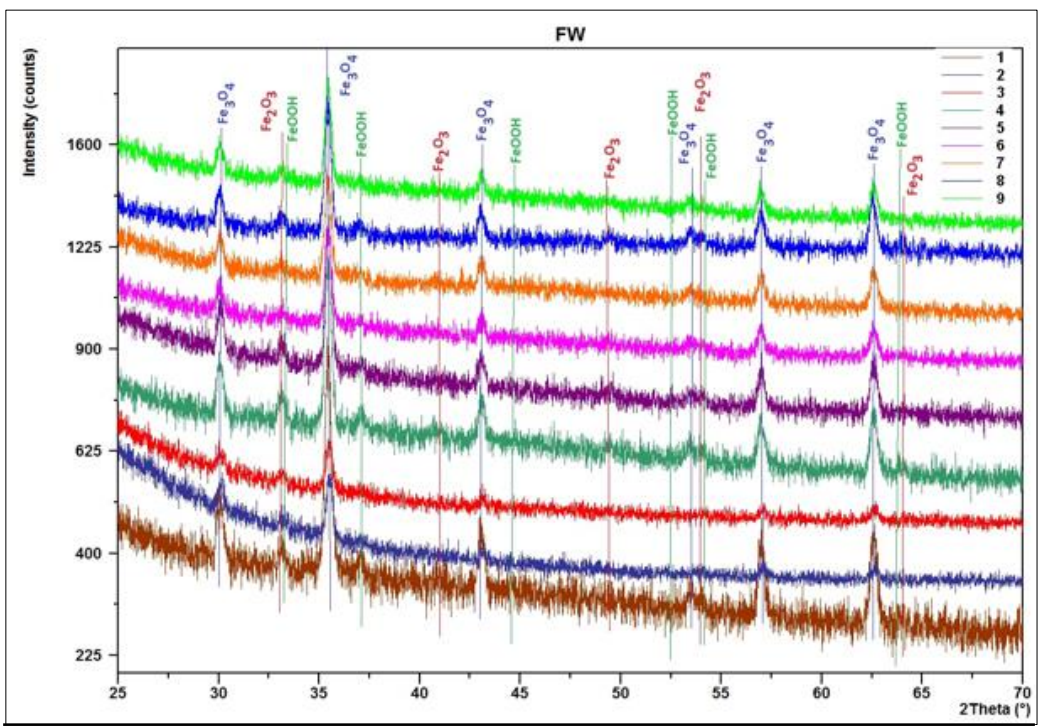

Fig. 5 Superposing of X-Rays spectra corresponding to the all Millipore filters extracted from feed water header $(\mathrm{FW})$

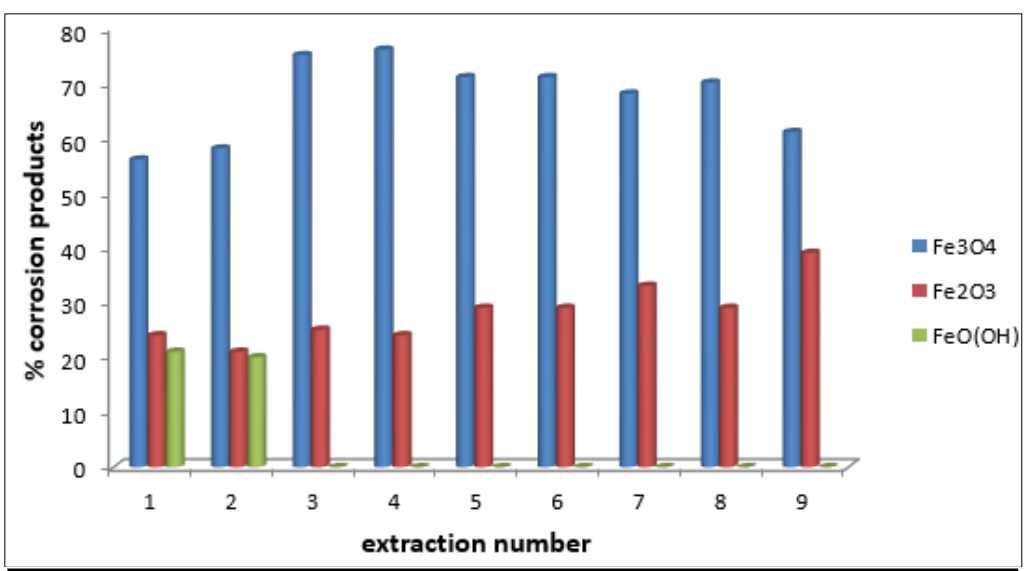

Fig. 6 The crud composition on the Millipore filters extracted from feed water header (FW)

Figure 7 shows the superposition of X-rays patterns corresponding to the filters extracted from blow down of steam generator (BLD). The compounds identified in the crud retained on the filters surface are: cubic, orthorhombic or rhombohedra magnetite; rhombohedra hematite; and cubic sub stoichiometric magnetite $\mathrm{Fe}_{2.964} \mathrm{O}_{4}$.

It was observed that, during the analysed period, the percentage of magnetite is maintained around $70 \%$, higher than that of hematite (Figure 8). 

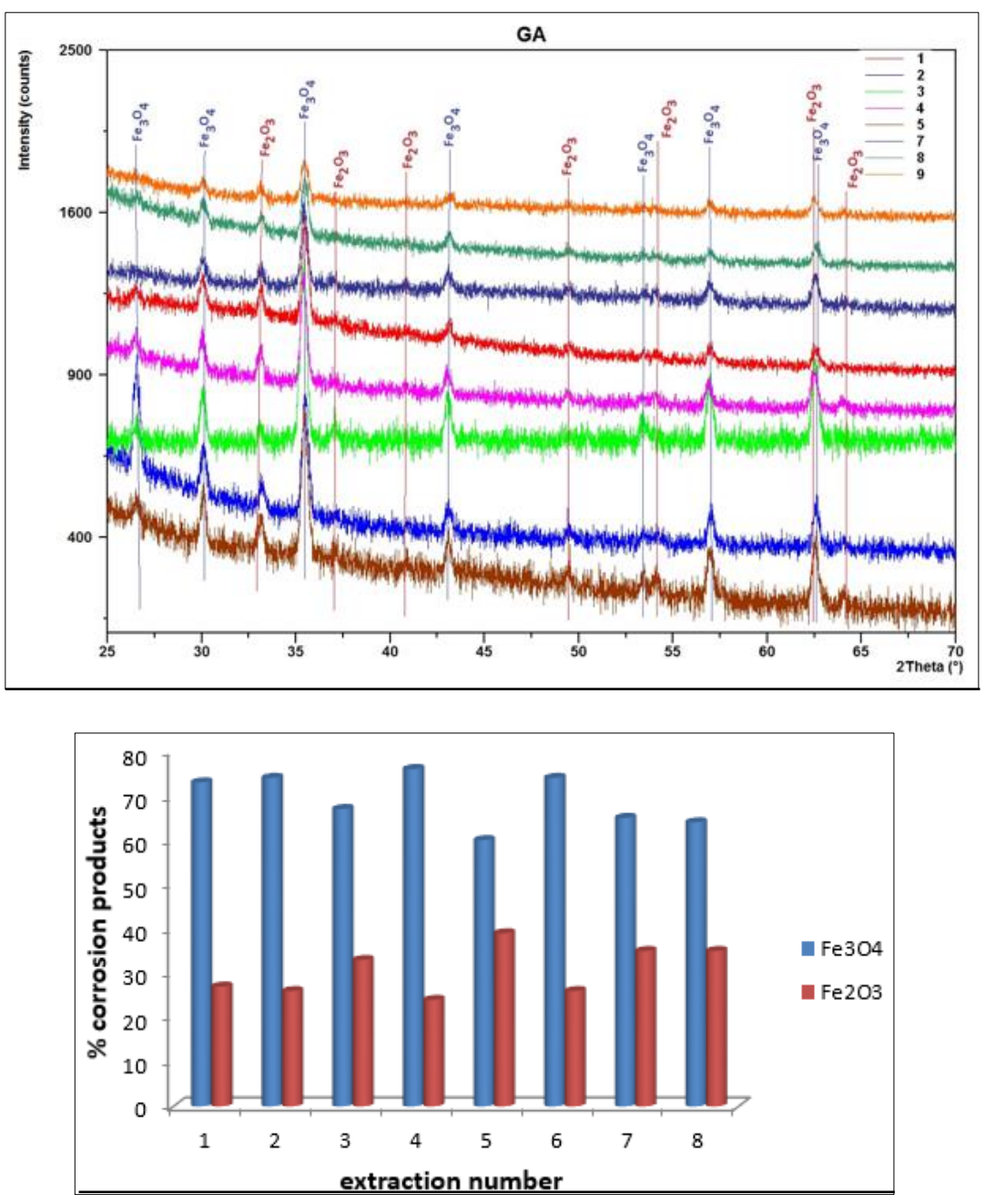

Fig. 7 Superposing of X-Rays spectra corresponding to the all Millipore filters extracted from blow down of steam generator (BLD)
Fig. 8 The crud composition on the Millipore filters extracted from blow down of steam generator (BLD)

From Figure 1 it may observe that are present the colours characteristic to the iron oxides: black that is associated with magnetite, respectively brown-reddish colour, specific to hematite $\left(\alpha-\mathrm{Fe}_{2} \mathrm{O}_{3}\right)$ and iron oxide hydroxides. These sustain the results obtained by GIXRD.

\section{Conclusions}

The corrosion products transported in the secondary circuit of a CANDU NPP were identified by analysing of the "crud" existing on Millipore filters located in some areas of the secondary circuit, namely: condensate extraction pump, header feed water, boiler blow down.

The analysis of corrosion products retained on the FW header filters provided data about the water chemistry: the presence of the magnetite as main corrosion product indicates that is maintaining a proper chemistry of the supply water from the secondary circuit of the plant.

The characterization of the corrosion products at the outlet of the condensate extraction pump revealed that the corrosion products are represented by: magnetite $\left(\mathrm{Fe}_{3} \mathrm{O}_{4}\right)$, hematite $\left(\mathrm{Fe}_{2} \mathrm{O}_{3}\right)$ and, in smaller concentrations, hydrated ferric oxide (lepidocrocite or goethite).

The corrosion products retained on the blow down of steam generator filters consisted of magnetite (major compound) and hematite and shows that water chemistry in the steam generator at optimal parameter are maintaining.

We can conclude that the X-rays diffraction analysis of solid suspensions retained on the Millipore filters is a very useful method to examine the chemical species transported through the secondary side of a CANDU NPP with the aim to evaluate and optimise the chemistry of cooling water.

\section{References}

1.LUCAN D., Nuclear Power Plants, Editors George Petridis and Dimitrios Nicolau, Chapter: Corrosion of the secondary side steam generator in the presence of impurities, Series: Nuclear Materials and Disaster Research Physics, Research and Technology, Nova Publishers Publishing, New York, USA, 2012, p. 197.

2.RADULESCU M., PÎRVAN I, DINU A., FULGER M., LUCAN D., Influence of the Secondary Circuit Chemistry on the Characteristics of the Filmed Carbon Steel Components, $5^{\text {th }}$ International Seminar on Primary and Secondary Side Water Chemistry of Nuclear power Plants, Eger, Hungary, 2001.

3.RADUlESCU M., PÎRVAN I, DINU A., FULGER M., ANGHEL C., Corrosion 2002, 7-11 April, Denver, Colorado, USA, Proceeding on CD-ROM, Paper No. 02527. 
4.KIM A.J., Corrosion, 51, No 11, 1995, p. 849.

5.KIM A.J., Corrosion, 55, No 1, 1999, p. 81.

6.DINU A., Journal of Nuclear Engineering \& Technology, 2, No 2, 2012, p. 11.

7.ZOTICA D., Cernavoda NPP - Boiler and Steam Cycle Chemistry Control, $5^{\text {th }}$ International Seminar on Primary and Secondary Side Water Chemistry of Nuclear power Plants, Eger, Hungary, 2001.

8.SARDELA M., X-Rays analyses methods, 2008 Advanced Materials characterised methods Workshop, Illinois, USA, 2008.

9.BERGE B., LENNE P.F., RENAULT A., Curr. Opin. Colloid Interface Sci., 3, 1998, p. 321.

10.BOUROUSHIAN M., KOSANOVIC T., Crystal Structure Theory and Applications, 1, 2012, p. 35.

Manuscript received: 14.06 .2018 
